\title{
ËSÁASI EWEERA: EN EL LABERINTO DEL ESTADO DUAL ${ }^{92}$
}

\author{
José Fernando Siale Djangany ${ }^{93}$ \\ Centro de Estudios Afro-Hispánicos (CEAH)
}

Resumen: El interés de esta monografía es interrogarnos acerca de la políticade la Monarquía española en la Isla de Fernando Poo entre 1892 y 1910; lapso en el que se desarrolló en Fernando Poo una actuación criminal "periférica" estrechamente varada en los arcanos de la soberanía monacal ibérica. Esta perspectiva conduce a la simetría entre los actos del Gobierno colonial y los designios del proceso ocupacional de la España del S.XIX y XX. Correspondencia de igual forma palmaria entre los acontecimientos del valle de Moka (1904) y el levantamiento de Balachá (1910). Resumiendo: poner de manifiesto que a lo largo de los dieciocho ańos que cubren los estragos de Batete (1892), la muerte de Ësáasi Eweera (1904) y la del bötúkku Lubbà (1910), las políticas de hostilidad y dańo deliberado a las condiciones de vida bubi fueron crímenes contra el derecho de gentes y se enmarcaban en los arcanos de soberanía españoles.

Palabras Clave: Ësáasi Eweera - Lubbà - Bubis - Levantamiento - Fernando Poo - Estado dual

AвSTRACT:: This paper examines the policies of the Spanish monarchy in the island of Fernando Poo between 1820 and 1910, a period in which Fernando Poo suffered "peripherical" criminal actions which were deeply grounded in the depths of Iberian ecclesiastical sovereignty. This point of view finds a symmetry between the actions of the colonial government and those of Spain's occupational process during the 19th and $20^{\text {th }}$ centuries. This correspondence is also very evident between the events of the Moka Valley (1904) and the uprising of Balachá (1910). In short, we aim to show that during the eighteen years that span from the Batete repression (1892) to the death of Ësáasi Eweera (1904) and of bötúkku Lubbà (1910), the policies of hostility and deliberate

92 Este trabajo ha sido realizado en el marco del Proyecto de Investigación HAR201234599 titulado "Lo que sabemos, ignoramos, inventamos y deformamos acerca del pasado y el presente de Guinea Ecuatorial. Revisión crítica multidisciplinar y nuevas vías de investigación".

93 sialedjangany@msn.com 
harm to the life conditions of the Bubis were crimes against the Ius Gentium and were framed within the depths of Spanish sovereignty.

KeYwords: Ësáasi Eweera, Lubbà, Bubis, uprising, Fernando Poo, dual State.

\section{EL ESTADO DUAL EN FERNANDO POO}

En la España de los años de referencia, se dan en la isla de Fernando Poo las características de un Estado dual; que es aquél donde coexisten un Estado normativo sometido al imperio de la ley (el Ministerio de Estado); y un Estado discrecional anclado en el criterio de la oportunidad (el Gobernador y la Iglesia Católica en Fernando Poo). Los dos Estados, el normativo y el discrecional, compartían ocultamente unos arcana imperii, misterios del imperio español con relación a la Isla de Fernando Poo. Empero, si el Estado normativo se ubicaba en apariencia en el marco de la legalidad y de la moralidad, ocultando actuaciones ilícitas pero útiles para la colonización, el Estado discrecional recurría a supuestos casus belli para ocupar y dominar la Isla y sus habitantes. Este Estado discrecional era, retomando la tesis de Norberto Bobbio, "un gobierno que actúa en la oscuridad más perfecta [...] para obtener beneficios ilícitos y recabar ventajas no consentidas por una acción a plena luz" ${ }^{4}$ (Bobbio 2013). La dualidad del Estado y los arcanos de soberanía garantizados en tal desdoblamiento se sustentaron y se maquillaron a través de una retórica de la disimulación tendente a silenciar los hechos, decirlos a medias, y eludir de pasada las responsabilidades relativas a la transgresión del ius gentium. Los sucesos de Biapa Alto y la insurrección de Balachá fueron precedidos por acontecimientos continuados que contribuían al arraigo de las circunstancias y actos con propósito que caracterizaban la observancia de los arcana imperii. Estos mismos historiales ahondan en la identificación de la intencionalidad. Y más allá de la intencionalidad es dable ver, inherente en los mismos, la conspiración para delinquir; que existe cuando dos o más personas se ponen de concierto para preparar y perfeccionar actos criminales.

\footnotetext{
94 Bobbio 2013, pp. 30-31: "criptogobierno es aquel ente que precisamente actúa en base a un mero juicio de oportunidad en la oscuridad del Estado normativo, para llevar a cabo deberes de los arcana imperii que han de mantenerse ocultos; pues sin tal oscuridad no podrían llevarse a cabo sin escándalo ni oposición”.
} 


\section{A PROPÓSITO DE LA GOBERNACIÓN DE ËSÁASI EWEERA}

Los académicos no se ponen de acuerdo sobre cómo llega Ësáasi Eweera a ser el bötúkuböóte. Unos apuntan que tras fallecer el bötúkuböóte Möókáta (febrero, $1899)^{95}$, sucedióle por breve tiempo el heredero Malabo Löpèlo Mëlaka. Éste implementa una política de sometimiento al Gobernador y a los Claretianos. En el año 1900, Ësáasi Eweera, miembro de la cohorte de Möókáta, se conjuraría contra Malabo Löpèlo tomando el poder. La otra versión subraya que Möókáta muere efectivamente en 1899 dejando dos hijos: Malabo y Bioko. Los pueblos de Biapa Alto se dividieron, prefiriendo algunos al menor, Bioko, debido al carácter complaciente con los blancos de Malabo. Ante el conflicto sucesorio, se llegó a una solución consensuada sorteando como jefe a uno de los hombres de confianza de Möókáta, Ësáasi Eweera, quien asumiendo el liderazgo defiende sin concesiones el derecho a la autodeterminación de los bubis; posicionamiento que le valdrá la aversión del Gobierno español y de la Iglesia católica. En su libro Los bubis en Fernando Poo, A. Aymemí refiriéndose a Sas Ebuera, escribe: "pocos años debía durar su reinado, el Gobierno se vio forzado a castigar la rebeldía de Sas, de Passi su comandante y de Bioko su instigador..." (Aymemí 1942: 194).

\section{ANTECEDENTES Y CRONOLOGÍA.}

\section{Factores determinantes.}

La jurisprudencia internacional en materia de genocidios establece que una intención específica puede ser inferida de los hechos, las circunstancias concretas o de un 'patrón de actos con propósito'. Y el concepto de la intencionalidad en la tentativa considera ésta como un acto punible en el mismo grado que el resultado. Considerando que no se puede conocer la verdad sobre los hechos referidos en esta monografía salvo atendidas las circunstancias que autorizaron los mismos, es significativo apreciar la realidad político-económica y religiosa que, entre 1892 y 1910, impulsa las actuaciones bélicas causantes de la muerte de Ësáasi Eweera y de Lubbà. En las dos circunstancias intervino oportunamente un casus belli, tanto relacionado con la negativa de los bubis en irse a las Misiones católicas, como a la de entregarse para prestación personal obligatoria. Así que importa centrarnos

95 Beltrán Rózpide da como fecha el mes de marzo de 1899; año que efectivamente confirma la Crónica claretiana del P. Pereda, señalando haber asistido a los funerales de Möókáta el Rdo. P. Pablo Pardina. 
en las circunstancias que residen en el por qué y cómo de la presencia de bubis en la Misión de Concepción, en el apoyo que proveyó el Gobierno colonial para ello, y en el juramento que mutuamente se hicieron en San Carlos León Rabadán y Lubbà en julio de 1910 con respecto del trabajo forzoso.

En una carta de 18 de marzo de 1892 dirigida al P. José (Josep) Mata, describe el P. Joaquim Juanola las amenazas al bötúkuböóte Möókáta: "A las puertas mismas de Moca estuvimos [...] como él estuviese quejoso porque los niños y aún las niñas iban a la Misión, el Sr. Comandante le cantó la cartilla y le dijo: Esto es lo que debe ser, y cuidado con molestar a la Misión; si no, estas armas que traigo para defenderte y que te respeten todos los bubis, serán para castigarte. Y así se hizo en todas partes respecto al Gobierno y a la Misión".

Estamos indubitablemente ante un patrón de actos con propósito. La Crónica claretiana de la Misión de Concepción, recopilada por el RP Bienvenido Pereda en febrero de 1929 hace referencia a la expedición del P. Puente a la Comunidad aldeana de Ësàasi Eweera: "Le recibieron con una salva de tiros. Salió luego su majestad (risum teneatis) ${ }^{96}[. .$.$] y mutuamente conversaron por medio de$ intérprete. Entre otras cosas le dijo, "si hacéis bien seré vuestro mejor amigo, y, ¡pobre del que os atropelle! Pero si obráis mal, os castigaré también porque tengo poder para matar al que lo merezca". Al pedirle el P. Puente a Sas que hiciera obligatoria la asistencia a la catequesis, Sas le respondió: "los bubis no somos como los blancos".

Por su parte, el P. Juanola da un paso más en otra carta, ésta de 18 de marzo de 1896 al mismo P. José Mata, en la que se enorgullece de que "en Bahú, distrito bubi al este de la isla [...] hubo una palabra [...] en virtud de ella fue requerido [...] el muchuku o jefe de los bubis de Bahú a que se presentara a la capital [...] El jefe de los bubis, como siempre, se negó [...] Entonces ya el Gobernador [...] se vio en la precisión de desembarcar la tropa y subir él mismo a castigar a dicho pueblo [...] destruyó las viviendas de dicho jefe [...] pero sobre todo vieron [los bubis] a su más temible enemigo, los krumanes, dispuestos siempre y con machete en mano al lado del Gobierno español" (Creus 2002: 19-32-33-34) ${ }^{97}$.

96 Contuvimos la risa

97 La hostilidad de los krumanes hacia los bubis ha sido descrita, entre otros, por Nuria Fernández Moreno en su estudio Bubi Government at the End of the 19ht Century: Resistance to the Colonial Policy of Evangelization on The Island of Bioko, haciendo hincapié en las confrontaciones de los años 1841, 1845-1848 (Nordic Journal of African Studies 22 (1\&2): 23-48 (2013). 
Del Gobernador decía Beltrán Rózpide, citando Reales Decretos de 1858 y 1868, que "es árbitro de todo, pues está investido de todas las atribuciones 'discrecionales' que la naturaleza del país o la urgencia de un suceso imprevisto puedan hacer necesarias". Empoderamiento que extendió el Gobernador Eulogio Merchán (1892-1893) por resolución gubernativa de 27 de mayo de 1892, confiriendo a los P. misioneros superiores prerrogativas gubernativas en calidad de Delegados del Gobernador ahí donde existieran Misiones. "El 10 de julio de 1888 , cuatro meses y medio después de la fundación de la Misión católica de Concepción por el celebrado P. Juanola en el poblado de Balobép ${ }^{9}[\ldots]$ envió una embajada al P. Manuel Puente, Superior de la Misión, para notificarle que si los habitantes y jefes de los poblados de Kutari (Ködáari), Bepepe, Bolobé [...] con los Bolokos y demás pueblos vecinos a la Misión causasen daños o molestias a la Misión, se lo indicase con el fin de castigarlos según justicia [...] Porque tengo derecho de quitar la vida a los que contravengan a mis disposiciones"; dixit P. Joaquim Juanola (Aymemí 1942: 191). Estas ya son palabras mayores. El P. Juanola pone de manifiesto que la civilización tal cual ellos la conciben, lleva inherente la barbarie. Eweera entiende que la autodeterminación y la conservación de la forma de vida bubi implican la muerte de los que transgredan ese derecho. Desde acá se rompe la barrera posible entre la simple idea eliminacionista y el paso al acto de asesinato. Hacemos hincapié en los hechos religiosos por cuanto que "la causa católica es causa nacional" (Matarranz 2007:49). Y es de conocimiento público que los religiosos de la Misión de Concepción se quejaron reiteradamente de la resistencia y "arrogancia" del bötúkku Ësáasi Ewéera99.

La Crónica claretiana antes referida señala la férrea oposición de Eweera y de Bioko como causas de la desaparición de la Misión de Concepción ${ }^{100}$. En este

98 La Misión de Concepción se fundó el 23-01-1888 en el lugar donde entonces quedaba ubicado el poblado de Bolobé, si bien el edificio definitivo se levantó en 1987. El internado se inició con dos chicos bubis: Pedro Esau y Santiago Noñeolo (según escritura claretiana)

99 Según el relato de Mobajale-Dyevola Lele, la inquina hacia el bötúkku Eweera vendría de antaño, de cuando -como custodios de la bahía de Concepción- decapitó con sus hombres a quince marineros espańoles aventurados en dicha bahía (Bolekia2007: 45)

100 "Cierto día mandó Sas unos emisarios a la Misión reclamando tres mujeres que se le habían fugado. Añadía en tono amenazador que, de no acceder, al día siguiente bajaría a quemar la Misión [...] Dicho y hecho. Al día siguiente, la fiera, acompañado de otras fieras como él, se pusieron en camino, decididos a llevarlo todo a sangre y fuego. Menos mal que otros dos jefes de alguna más cordura increparon y desaprobaron su proceder [...] lo mismo había sucedido unos ańos antes con el astuto y judío Bioko [...] que no pudo rescatar a sus dos mujeres fugadas, declaró guerra a la Misión por medio del veneno [...] A esto se debe que la Misión no haya progresado". 
sentido, la correspondencia del P. Sotero Gómez a Joaquim Juanola el 27 de julio de 1904 se centra en gran medida en la oposición de Bioko y del bötúkku de Balachá de Riaba a los intereses de la Misión de Concepción. De lo anterior se sigue que la violencia del valle de Moka como resistencia primaria a la ocupación no puede apreciarse en toda su plenitud si no se relaciona comparativamente con el estrago de María Cristina de Batete (1892) ${ }^{101}$ y, sobre todo, con el levantamiento de Balachá (1910) ${ }^{102}$ como resistencia secundaria al dominio y la subyugación.

101 En sus memorias, el P. Ermengol Coll hace referencia a la correspondencia de Antonio Aymemi que alude a las consecuencias de la agresión del año 1892, provocada por muchachos de la Misión de Batete alzados en armas contra la Comunidad aldeana del Nabba Boabi, siendo muerto por arma de fuego un bubi de dicha aldea de manos de un joven pamue de la misión: "al enterarse (el P. Pinosa, Presidente del Consejo de Poblado de la bahía de San Carlos) de lo ocurrido en Batete, pidió auxilio al finquero moreno Guillermo Vivour y al encargado de la finca de Francisco Romera. Llegaron primero a Batete los krumanes de Vivour, los cuales subieron en son de guerra a las rancherías bubis [...] Mataron muchas cabras y robaron todos los ńames que pudieron [...] Al otro día llegaron los krumanes de Romera acompańados de dos blancos [...] los blancos mandaron a los negros que rociasen de petróleo las cabañas bubis [...] los blancos pegaron fuego a algunas rancherías [...] los bubis tardaron bastante tiempo en presentarse y algunos se fueron a Ureka, otros a Balachá, otros a Bokoko [...] Con esto ganó la Misión muchísimo, pues los bubis se acobardaron tanto que ya no se atrevieron a alzar la cabeza; y, viendo los jóvenes acobardados a los viejos, se fueron bajando poco a poco a la Misión". En la correspondencia del P. Aymemí relativa a estos acontecimientos se revela el beneficio resultante de la represión, que también se evidencia doce años después en la locución del Primer Teniente de la Guardia Civil, José de la Torre, una vez fallecido Ësáasi Eweera: "nuestros Misioneros podrán ejercer su ministerio sin la resistencia que ofrecía a sus propósitos un gobierno indígena que ya no podía tolerar, ni la civilización ni el decoro de nuestra Patria”. Lo ocurrido en Batete constituyó un segmento más en la premeditada erradicación de formas de vida colectiva en pro del control de un espacio vital para la Misión católica y, por ende, para la Monarquía española. En la narración de Aymemí aludida por el P. Ermengol Coll se certifica que dos cuerpos paramilitares kru-man debidamente organizados y armados, cometieron estrago, destrucción de aldeas, robo de ganado. Que los bubis, viéndose en peligro, abandonaron sus tierras. El delito de estrago fue tipificado en el Código Penal español desde 1848, habiéndolo matizado el Tribunal Supremo como un daño de extraordinaria gravedad e importancia para cuya consecución el agente se vale de medios de destrucción suficientemente poderosos, poniendo en peligro a las personas.

102 Según el Diario Claretiano del mes de julio de 1910, los pueblos de Batete, Bokoko, Boloko, Basakato y Tuplapla acudieron al llamamiento del Gobernador acerca de las condiciones de la prestación personal bubi. Los pueblos de Balachá, salvando Batete, no asistieron a dicho encuentro. Afirman nuestros informantes de Ruiché, Ômböri, Belebú de Balachá, Bokoricho, Böemëriba, que las muertes y condiciones inhumanas de trabajo en las faenas de prestación personal para el dragado y dique de la carretera y puente de San Carlos fueron la razón por la que el bötúkku Lubbà reuniera a los pueblos de Balachá sobre el particular (el artículo de Mariano Fernando Montserrat en La Guinea Española, Año VII, No 17 de 10-091910, señala la muerte de más de 40 bubis por las fiebres contraídas durante la prestación personal). En la reunión de Balachá a la que acudió el gran bötúkku Táböri, todos los 


\section{De Santa Isabel a la bahia de Concepción (segunda quincena de junio de 1904).}

La cronología de los actos del valle de Moka constituye un elemento crucial en la interpretación de los arcana imperii por el criptogobierno de Santa Isabel. También sostiene válidamente la premeditación en la materialización de los actos consecuentes. El 22 de diciembre de 1902 se nombra Gobernador General de Fernando Poo a José de Ibarra y Autrán, individuo con poquísimos estudios elementales. El 18 de febrero de 1903 Ibarra y Autrán regresa a Fernando Poo tras seis meses de consulta en España. Por Real Decreto de 31 de diciembre de 1903 es cesado como Gobernador ${ }^{103}$ al suprimirse la Estación Naval del Golfo de Guinea de la que era Comandante. Empero sigue en el puesto hasta la Real Orden de 15 de febrero de 1905 por la que se le destituye definitivamente.

bötúkkus de Balachá tomaron la decisión de negarse a la prestación personal obligatoria. Cuenta Milagrosa Lubbà, tataranieta de Lubbà, de Böemëriba: "Lubbà bajó a San Carlos para discutir con Pedrasa. Estaba totalmente vestido de sus eppà de tyibbo, no iba armado... los españoles atraparon a un bubi. Entonces Lubbà se enfadó y a su vez mató a un blanco con su ekatyavöla (fusil de chispa avancarga con pólvora). Puede que no sea el mismo día sino a la mañana siguiente. Los blancos dijeron, ¡un bubi no puede matar a un blanco!, y mataron a Lubbà. Lo enterraron a la entrada de la ciudad de San Carlos, por donde hay un monumento, y colgaron su ekatyavöla en la vivienda de Pedrasa. En la época de Macías esa escopeta seguía ahí." [testimonio recogido en Böemëriba el 9 de agosto de 2015] Dice con más claridad el memorioso Bulebiele Mbátösula (Belebú de Balachá, 16 de agosto de 2015): "A finales del mes de julio de 1910, bötúkku Lubbà bajó a San Carlos a aprovisionarse en la factoría de Magatzims. En San Carlos se cruzó con León Rabadán quien le increpó por su rebeldía. Se discutieron. A lo último el blanco le dice, ¿tú insistes en que no cogeré trabajadores en tu jurisdicción? Es así, le dijo Lubbà, si es para que nos exterminemos, nos exterminaremos, pero nadie bajará más. ¿Quieres hacer una apuesta? El blanco dijo sí, entonces sacó una moneda de cinco pesetas, dinero de Alfonso, y el bötúkku sacó de su mochila una moneda de dos cincuenta, de las que tenían agujero en medio, y le dijo ¡toma! Cada uno cogió la moneda del otro. Lubbà subió cabreado al pueblo e hizo sonar la trompera para una reunión a la mañana siguiente, informando a la gente de la apuesta que había hecho. Así que, les dijo durante la reunión a la que asistieron representantes de todos los pueblos de Balachá, debemos estar preparados, si sube ¡hay que disparar! Que pase lo que pase. Un día de esos ese blanco subió, pasando por Musola, ahí en Comproví donde está el campamento de Mioko, recoge a su gente y empieza costeando por los senderos hasta la zona de Bokoricho-Grande donde encuentran a dos aldeanos que venían de sus palmeras y ordena a los militares que los atrapen. Los soldados sólo consiguen apresar a uno. El otro huye por el bosque hasta llegar a Ömbôri, informa a Lubbà de lo ocurrido. Lubbà salió enfadado, cogió su escopeta; su esposa Riömmo fue tras él, cantando y tocando un cuerno de búfalo. Cuando Lubbà encontró a León Rabadán, disparó y lo mató. Uno de ellos sobrevivió pero herido. Se escapó y regresó a San Carlos".

103 Cese publicado en la Gaceta de Madrid de día 10 y14 de febrero de 1904, Tomo I p. 625, Año CCXLIII -No 45 
Entre tanto, perfecciona sin trabas los sucesos del valle de Moka y el homicidio de Eweera. Es notable que la Hoja de Servicio de este señor como miembro de la Armada concluya en noviembre del ańo 1890 siendo brigadier. Una vez nombrado Gobernador su currículo se congela en el legajo militar de Segovia, donde no existe nada relacionado con su actuación como Comandante de la Estación naval del Golfo de Guinea, ni como Capitán de Fragata de la Armada y jefe superior de Administración civil y Gobernador General. Por otro lado, el 19 de febrero de 1904 José de la Torre y Reyes (con un largo historial militar; habiendo entrado en el Regimiento de Caballería Hernán Cortés el 8 de diciembre de 1886 y nombrado Primer Teniente de la Guardia Civil el 19 de julio de 1898) asume el mando del Cuerpo de Policía y Seguridad en la colonia de Guinea. Como en el caso de José de Ibarra, la Hoja de Servicio de José de la Torre no contiene información alguna después de 1898 acerca de su presencia en Fernando Poo.

Narra Mobajale-Dyevola Lele que un bubi, ex miembro de la cohorte de Ësáasi, de nombre Roòbi, formuló denuncia ante los claretianos, alegando haber sido agredido en su pueblo, Ködáari, por un mandatario de Eweera llamado Vilobbè, debido a su propensión al catolicismo. En virtud de aquella denuncia, antes del 27 de junio de 1904 un grupo de soldados indígenas salió de la Guarnición de Concepción hacia el valle de Moka. Siendo rechazados enérgicamente de la aldea de Ësáasi Eweera, Maiye (LGE 1904, no 32, 12 de julio); regresaron horas después a la Comandancia de Concepción.

En la crónica sobre "Movimiento de Barcos", el vapor Mogador de la Compañía Transatlántica de Barcelona salió del puerto de Santa Isabel para la bahía de Concepción el 25 de junio llevando a bordo efectivos de la Guardia Colonial dirigidos por José de la Torre y Reyes, Primer Teniente de la Guardia Civil; Fausto Andrés Aliaga, oficial de la Guardia Civil; Silman Sila, Cabo, mercenario africano de la Guardia Colonial; José Sabater, Capitán del vapor Mogador. Desembarcados en la Bahía de Concepción son albergados en la Misión claretiana el mismo día 25 de junio por los Padres Salvador Puig y Sotero Gómez. José Sabater se quedó en el Mogador. Horas después la guarnición encabezada por el Cabo Silman Sila tomó rumbo hacia el valle de Moka. Se desprende de la correspondencia del Delegado de San Carlos ${ }^{104}$, de fecha 28 de marzo de 1905, que tanto Fausto Andrés Aliaga como José de la Torre y Reyes permanecieron en la Misión; así que solamente Silman Sila y los otros soldados subieron a por Ësáasi Eweera.

${ }_{104}$ Quien también viajó en el Vapor Mogador si bien por otros motivos según lo declara el mismo 


\section{Valle de Moka y regreso a Santa Isabel}

Existen dudas acerca del número de hombres que compusieron el cuerpo expedicionario, por lo tanto habrá que estimarlo por deducción. Pero sí hay datos sobre la clase de armas y municiones de que disponían los beligerantes. Los bubis utilizaban lanzas-jabalinas y flechas envenenadas, fusiles de chispa ${ }^{105}$. Señala el teniente José de la Torre en su declaración acerca de la muerte de Ësáasi Eweera, que éste "disponía de buen número de hombres obedientes a sus mandatos, armados con armas primitivas y escopetas de pistón y chispa". Resulta de la Memoria del Ministro de Estado a las Cortes sobre situación política y económica de las Posesiones Españolas del África occidental en el año 1910, que el armamento de la fuerza de la Guardia Colonial era el Máuser para clases europeas y el mosquetón sistema Reminghton para las guardias indígenas ${ }^{106}$. En cuanto al número de elementos, el P. Antonio Aymemí dice "un buen número de soldados indigenas". Referencia que se acerca al testimonio de Mobajale-Dyevola Lele, quien habla de un centenar de soldados. En su separata "Exploradores científicos de la Guinea" (1946), Caridad Robles Mendo alude a 30 krumanes, más los marineros europeos del Pontón Ferrolana, José Aguirre, Joaquim Juanola y Sorela. Estas conclusiones contradicen el informe de José de la Torre y Reyes de 30 de junio, que señala que además de Fausto Andrés Aliaga, salieron de Santa Isabel dos cabos y seis soldados indígenas. Enfrente, José de la Torre señala "un buen número de hombres" (bubis). Nuria Fernández Moreno (2013) hace alusión a la presencia de una suerte de ejército bubi encargado de la seguridad territorial y de la del bötúkku' ${ }^{107}$.

105 Según la información prestada por el memorioso Bulebiele Mbatösula de Belebú (agosto de 2015) en la revuelta de Balachá los beligerantes bubis utilizaron -además de las lanzas envenenadas- como metralla para sus fusiles de chispa fragmentos de lima y de ollas desmenuzadas, cuando no les quedaban perdigones reglamentarios. Esta práctica venía siendo utilizada por los cazadores bubis. El informante Sakká Mueï señala el Tôékkè para la fábrica delas jabalinas, y el mimbre Löhahá para la concepción de los arcos.

106 Jesús Núńez. Revista "ARMAS” no 248, diciembre de 2002. Editorial Paul Parey Madrid-28.043. La tropa indígena fue dotada inicialmente del fusil monotiro Remington, modelo 1871-89, calibre $11 \mathrm{~mm}$., adoptado por R.O.C. de 13 de abril de 1889 y su correspondiente bayoneta. Si bien dichos fusiles fueron declarados caducos por R.O.C. de 26 de marzo de 1909, se mantuvieron en servicio.

107 "These political-war societies of the buala, in addition to judging and executing sentences in the towns, were in charge of the government and defense of each region" (Martín del Molino 1989: 485). 
Cuando Joaquim Juanola, acompañado del oficial Luis Sorela (o viceversa, según quién cuenta la historia), fueron en "son de paz" a hacerle una visita a Möókáta en el año 1887, precavidamente se hicieron acompañar por veintidós krumanes armados. A propósito de este viaje, Caridad Robles Mendo alude a las palabras de Luis Sorela, en contradicción con el revisionismo subyacente en la idea transmitida de la "visita de cortesía" al rey Moka: "Las carabinas Winchester les hicieron ser respetados por aquellos salvajes, que hubieran dado buena cuenta de sus vidas" (1946:75). Las descripciones de Juanola y Pujadas de la impresión que tuvieron al encontrar al bötúkkuböóte, dan una idea acerca del poder e influencia política y militar de que disponía Ësáasi Eweera, y la capacidad que había de reunir un número importante de luchadores. Es obvio por consiguiente que los ocho elementos (un Escuadrón) a que aluden los documentos oficiales, no son un buen número teniendo en cuenta la estrategia elemental consistente en ser más numerosos y mejor armados que el contrario ${ }^{108}$. Del löhúúa dijo Pujadas que se trataba de una tropa de cientos de hombres dotados de fuerza pujante. Según relata también Ibrahim Sundiata ${ }^{109}$.

108 En los sucesos de Balachá en julio de 1910, según los relatos académicos, León Rabadán subió a Balachá sólo con 3 soldados y fueron, salvo uno que llegó herido a San Carlos, sencillamente matados. Posteriormente desde San Carlos subieron hacia Balachá 2 cabos y 10 soldados, encontrando una resistencia que no pudieron someter. A la tercera, subieron 80 soldados africanos. En el Diario Claretiano de julio de 1910 se lee lo siguiente: "El 21 de julio el Delegado José Barina y unos pocos hombres subieron para parlamentar con los de Balachá, y fueron recibidos a tiros. Tan luego llegó la noticia se armaron todos los blancos y con unos 200 o más morenos subieron a defender al Sr. Delegado y a repeler a los bubis. Casi todos los blancos bajaron heridos, y muchos morenos [...] La lancha Ena llegó de Santa Isabel en la noche del 21 de julio con el teniente Dámaso Gonzáles acompañado de varios cabos blancos y unos 25 números de la guardia morena. El 22 por la mañana subió la fuerza, acompañada de algunos blancos y de varios morenos y trabajadores. El tiroteo fue muy vivo". Nos cuenta el memorioso Bulebiele Mbatösula: "El Papá Ehoso de este pueblo, que ya murió, era quien tocaba el bötuttú (el cuerno de alerta y orden de ataque) en los senderos de este lado del bosque. Mi abuelo, el padre de mi madre, también estuvo en esa guerra, se llamaba Mbatösula, y mató a doce personas. La guerra duró 3 días. De la información recibida del abuelo Sora Mössëpà (nacido en diciembre de 1936) y de la abuela BiatyóTöttè (86 años) de Ruiché el 30 de agosto de 2015, así como de la informante MC Ferro Tokotobe (Bokoricho, 3 de septiembre 2015), el bubi llamado Thomos Boselle (Mobbio) estuvo al lado de Lubbà en el momento de la muerte de León Rabadán y de los otros soldados y participó activamente en la insurrección de Lubbà. Siendo MC Ferro Tokotobe una niña, Thomos Boselle le enseñó las heridas de perdigones que en dicho enfrentamiento recibió en el brazo derecho".

109 "Una de las claves que ayudó a reforzar el control de Moka sobre los jefes de otras aldeas fue su superioridad militar. Moka creó el LUJUA para controlar todas las ciudades del sur y poner fin a los combates continuos entre ellos. Autores que fueron contemporáneos de Moka, como Navarro (1888), definen esta institución como un cuerpo armado que viajaba de pueblo en pueblo para aplicar la ley, la imposición de la justicia y la recolección de tributos 
Además de su número, el personal militar enviado a Concepción y al valle de Moka gozaba de experiencia belicosa. En la Hoja de Servicio del Archivo militar de Segovia consta que José de la Torre es hombre de valor acreditado y de mucha táctica militar. En el año 1873 se le instruyó sumario y purgó un mes de cárcel por propender al abuso de autoridad. A partir de 1874 José de la Torre Reyes participará en prácticamente todas las batallas y batidas libradas contra los cubanos. En 1876 se le promocionará a Cabo $1^{\circ}$ por méritos acopiados en los Montes de San Joaquín, y se le concede la Cruz Roja del Mérito Militar por sus hazañas en la batalla de Santiago del 18 de abril del año anterior. Las descripciones que se dan de Silman Sila autorizan presumir la clase de acción que le encomendaban llevar a cabo aquellos a quienes estaba acostumbrado a obedecer: "El elemento indígena es sobrio, subordinado, y gran cumplidor de las órdenes que se le dan"110 . De Silman Sila apunta el Gobernador en la correspondencia de 26 de julio al Ministro de Estado, que es hombre de intachable valor que tenía ya prestados, como policía, muy buenos servicios en la colonia. El eufemismo consistente en que un soldado haya prestado leales servicios, es ya un lugar común. Lo describen así los claretianos en La Guinea Española, no 32, 12 de julio 1904: "el cabo Scila, senegalés, hombre templado, inteligente y nada cobarde, hace años presta valiosos servicios en la colonia [...] iba debidamente instruido por su jefe el Sr. Teniente de la Guardia Civil, subió a Moka, al frente de los suyos, convenientemente armados". En este retrato se enmarcan, además de la propensión patológica del mandatario a cumplir con toda orden dimanante del mandante, la premeditación y el complot: "debidamente instruido y convenientemente armados". El resto va de suyo. Escribe Rosa-Amelia Plumelle Uribe que "por lo general, cuando un Blanco decidía hacer torturar a un Negro, el verdugo encargado para la ejecución era un negro" ${ }^{111}$. Silman Sila no dejó testimonio alguno de lo que acometió.

en ciertas épocas del año. Esta milicia judicial estaba compuesta por el baribidi, el grupo más veterano de los bubis... Por debajo de ellos, el segundo rango militar consistió en la basalicopo, y por último, estaba el baricaná, la tropa de hombres jóvenes" (Sundiata 1996: Abate 1901, Sorela 1888)

110 Informe del Ministro de Estado a las Cortes sobre situación de las Posesiones Espańolas en África occidental para el año 1910.

111 Este patrón se dará perfectamente en la revuelta de Balachá donde, según cuenta el memorioso Bulebiele Mbatösula: "solamente murieron los negros, muchos negros, cameruneses, monrovianos, ghaneses, nigerianos, senegaleses, togoleses, los blancos manejaban a los negros, murieron muchos africanos, un solo blanco murió, Rabadán. Los bubis se escondían apostados y atrincherados en los bosques cercanos a los senderos, los soldados negros no conocían el bosque, subían por los caminos y senderos, y los bubis disparaban contra ellos. En 'bromas aparte' (un despeñadero bastante pronunciado cerca de Ömbôri) existía una escuela mixta de los balachá, y próximo a la escuela unos naranjos. En estos naranjos 
Entonces hablarán por él los adagios que rezan que "se presume hecho lo que se acostumbra hacer", porque "lo que es notorio no necesita probarse" y "a nadie debe sacarse de su casa contra su voluntad".

Las potencias imperialistas de principios del S. XX, siguiendo una tradición anclada en el S. XIX, se dedicaban a la calza y el ramal, al genocidio en las tierras ambicionadas. Los mercenarios kru-man traídos a la Isla de Fernando Poo a saldo del Rey Alfonso XIII, acostumbraban a servir a España con el machete y el mosquetón en la mano, haciéndose el peor enemigo del bubi. Encabezado por Silman Sila, el Escuadrón sorprende a sus víctimas al amanecer del día 27. "La lucha fue sangrienta. La masacre de los Bubis fue terrible" ${ }^{12}$ [...] Regresan a la bahía de Concepción el día 29 por la mañana trayendo consigo a Ësáasi Eweera, el sombrero y el bastón de mando de éste, varios rehenes incluidos niños, ganado robado, escopetas confiscadas. Tras un breve alto en la Misión católica bajan a la bahía donde embarcan en el Mogador rumbo a Santa Isabel. En su correspondencia de 12 de agosto de 1904 el Delegado de Gobierno de San Carlos, Amilivia, afirmó que, encontrándose en la finca de Manuel Balboa en la bahía de Concepción, vio llegar conducidos por fuerza de policía unos cuarenta bubis aproximadamente. El Mogador, por orden de su capitán José Sabater, ha fondeado durante cuatro noches en la Bahía de Concepción esperando el regreso de José de La Torre. Zarpa y llega a Santa Isabel el mismo día 29 de junio a las diecinueve horas. Del bötúkkuböóte Ësáasi Eweera no se sabe nada hasta que el día tres de julio es dado por Ibarra y Autrán como fecha de su fallecimiento ${ }^{113}$.

murieron varias personas. Era la época lluviosa y la sangre estaba chorreando en las cunetas y senderos como agua". La matanza de los naranjos también nos ha sido relatada por el abuelo Sora Mössëpà de Ruiché.

112 Mobajale-Dyevola Lele, in. Justo BolekiaBoleká, 2007

113 Empero, el médico del hospital de Santa Isabel declara que Sas Ebuera fue internado el día 2 de junio; mas a tenor de la revista La Guinea Española no 33, Sas Ebuera murió el día dos de julio. El P. Aymemí al igual que el Gobernador, contradicen sin embargo la información que da la revista La Guinea Española, que confirma el fallecimiento de Sas Ebuera en el hospital de Santa Isabel dos días después de embarcado en el vapor Mogador; es decir, que Sas expiró el día 1 de julio y no el día tres de julio como lo afirman el P. Aymemí y el Gobernador, ya que el Mogador llegó el día 29 de junio. 


\title{
EL LABERINTO DUAL AL SERVICIO DE LOS ARCANA IMPERII
}

\author{
Retórica de la disimulación y lirismo de mal gusto
}

Durante la sesión de la Junta de Autoridades de Santa Isabel de 21 de julio de 1904, el Juez de Primera Instancia e Instrucción de Santa Isabel sacó a colación el tema de haber sido muerto Ësáasi Eweera en el hospital Reina Cristina de Santa Isabel. La intervención del jurista será el catalizador de una retórica de la disimulación por la que el Estado discrecional se calafateará en aquella "oscuridad perfecta" a que alude Norberto Bobbio en su definición de las zonas de actuación del criptogobierno. Precisamente porque la muerte del bötúkkuböóte entraba en los arcanos de soberanía fielmente interpretados por el Estado discrecional, el Estado normativo tenía el deber de desvincularse de tales actos, porque es el interés natural del Estado normativo ante las iniquidades del Estado discrecional ${ }^{114}$. Para ello se instrumentalizará una información administrativa tendiente torticeramente a averiguar si dicha muerte causó indignación o no entre los bubis y los "morenos más prestigiosos". Se excluirá de esta información a Silman Sila y los miembros de su Escuadrón. La pirueta del Gobernador, que reflejará en autos Francisco-Javier Gallo y Martínez de Maturana (13-08-1904), es la siguiente: "como quiera que la indignación por la muerte de Sas se hubiera podido producir entre los indígenas bubis, considerando que son los padres misioneros y el cuerpo

114 La simetría es perfecta con la actuación del Gobierno en los sucesos de Balachá (1910). El comisionado, para mantener ocultos los arcanos de soberanía es el Gobernador Angel Barrera, recién nombrado y desembarcado, mandatario especial para la "investigación" de lo acontecido con la muerte de Rabadán y Lubbà. Como en el caso de Sas Ebuera, el Gobernador interino que llevó a cabo la "operación”, Luis Dabán, es "sacrificado" como cabeza de turco. La riza de Balachá reiteró sin duda alguna que el Estado discrecional, el criptogobierno (Puesto Militar de Musola, Comandancia de San Carlos, Pedrasa, Gobernador interino, Junta de Autoridades de Santa Isabel, León Rabadán), estaba perfectamente interpretando los arcanos de soberanía del Estado español; y el casus belli aprovechado en este año fue la valentía y audacia de Lubbà, Bioko, Moòpé, Mbatösula, Thomós Bosselle, en pro del derecho a la autodeterminación. La diferencia entre los dos sucesos estriba en el resultado conseguido en el valle de Moka y la matanza frustrada en los sucesos de Balachá, por la simple razón, como lo cuenta el memorioso Bulebiele Mbatösula, que la insurrección de Balachá no se decidió de la noche a la mañana, era algo de lo que ya se venía hablando desde hacía mucho tiempo en varios encuentros de bötúkkus incluso con pueblos de la zona de Baney, Rebola, Basakato, Batoicopo, etc., mientras que en 1904 Ësáasi Eweera fue sorprendido, no pudiéndole apoyar otros pueblos. De hecho, cuenta Bulebiele Mbatösula, que el día 12 de agosto de 1910 varios luchadores originarios de Baney, Rebola y Basakato, habían tomado los senderos para unirse a los beligerantes de Balachá, pero llegados a las aldeas de Toplapla (actual zona de Batoicopo) recibieron información de la muerte de Lubbà y del cese definitivo de las hostilidades. 
de policía quienes se hallan en constante contacto con los bubis, pues recíbase en declaración a ésos". Mejor falacia argumentativa imposible. Las declaraciones así prestadas por gente al servicio del criptogobierno se revelarán meramente utilitarias; pues servían los propósitos del colonialismo español 'benevolente' que se debatía desesperadamente por distanciarse del mortífero colonialismo belga y francés.

La razón de ser de la información era una buena mentira montée de toutes pièces, que no se resistía a la prueba de la verdad ni a un razonamiento lógico. Si la muerte de Ësáasi fue natural, no pudo haber causado indignación en nadie; y si preocupa saber si causó indignación, es porque no fue natural; ya que la muerte natural de las personas ancianas o escarnecidas por la enfermedad por supuesto que no causan indignación, por lo menos en la costumbre bubi.

A raíz de la Información Instruida con Carácter Reservado, autorizada por despacho gubernamental No 1196 para diligenciar actuaciones por el oficial de segunda del Gobierno General (funcionario bajo la autoridad jerárquica y funcional del Gobernador) Francisco-Javier Gallo y Martínez, prestan su declaración no decisoria y sin juramento las autoridades religiosas y militares así como el mismo Juez Gonzalo de Cubells. También declara Arturo Gill Favre, médico con destino en el hospital Reina Cristina de Santa Isabel, ya que el Director de dicho hospital, el Dr. Manuel García, declinó responsabilidad en el médico Arturo por ser -según dijo Manuel García- quien atendía a los morenos, correspondiéndole por consiguiente declarar acerca de la muerte del indígena Sas Ebuera. Sin embargo, consta en el no 33 de la revista La Guinea Española que el Dr. Manuel García intervino personalmente en el tratamiento médico y amputación de la pierna de un moreno que llegó en mal estado físico en el mes de junio. ¿Recibió instrucciones perentorias en ese caso en particular? [...] De la Información Instruida por Francisco-Javier Gallo se desprende que lo expresado por el Juez de Primera Instancia se hizo de manera indecisoria. Resulta del legajo que todas las declaraciones prestadas lo fueron a título no decisorio, en el sentido de que los declarantes lo hicieron de tal manera que sus manifestaciones no constituyeran prueba plena. La prueba plena exigía, para constituirse (a fin de que las manifestaciones de Salvador Puig, Joaquim Juanola, Gonzalo de Cubellas, Arturo-Gill Favre y Sotero Gómez tuvieran fuerza vinculante), que otras pruebas objetivas fueran practicadas. No fue así. Además, las declaraciones exculpatorias de Juanola, Gómez, José de la Torre y Andrés Aliaga tampoco son válidas de por su 
fuente, porque "ninguno puede ser testigo en causa propia". Amén del hecho de que al estamento religioso-militar beneficiaban aquellos crímenes ${ }^{115}$.

Para dar respuesta al requerimiento del Ministerio de Estado de 16 de septiembre de 1904 RS No 437, José de la Torre evidentemente incurre en contradicciones, en falsedades y en anacronismo ${ }^{116}$. Según sus manifestaciones primero subió al valle de Moka. Apresó personalmente a Ësáasi Eweera. Lo trajo a la Misión de Concepción y le constriñó a declararse súbdito del Rey Alfonso XIII. José de la Torre retornó al valle de Moka donde quemó la casa de Eweera. Pero esas mentiras son lo de menos. ¿Acaso se precisa de mucha imaginación para detallar lo acontecido con Ësáasi, Pasi o Vilobbè y los habitantes de la Comunidad aldeana de Maiye? El patrón histórico del testimonio de la congolesa Ilanga de Waniendo (Plumelle Uribe 2001: 97-99) es exactamente lo que ocurrió en Maiye y de camino a la bahía de Concepción. La Isla de Annobón y Cabo San Juan ofrecen antecedentes vehementes que se incardinan en los arcanos de soberanía monacales ${ }^{117}$. Lola García Cantús ya desmenuzó en parte esa farsa, sobre lo que no creo necesario revenir. No obstante, es aquí dable señalar que

115 En este sentido, el 24 de julio de 1904 el P. Sotero Gómez de la Misión de Concepción escribe en respuesta a una correspondencia recibida del P. Juanola el día 20, una carta cuyo eje se centra en la primera pregunta que hace Juanola en la suya: “¿Cuántos (bubis) han entrado en la Misión desde que Sas desapareció?”; 45, responde Gómez. Joaquim Juanola revela aquí su perfecto conocimiento del obstáculo que representaba el jefe bubi, y de los logros que se derivarían de su "desaparición". Comparando, señala Eduardo Canals que en 1899 la Misión de Concepción cuenta con diecinueve familias asentadas en la calle de la Esperanza, y se está extendiendo la evangelización hacia el Norte y el Sur (Canals, 1993: 131).

116 El uso de la mentira y la retórica de la disimulación se emplearán de nuevo en los acontecimientos de Balachá, con la intención de ocultar dos realidades: 1) que el ejército español sufrió muchísimas bajas, 2) que el gobierno español solamente se interesó por el cadáver de uno de sus soldados, León Rabadán, el único blanco muerto, abandonando en el bosque el despojo de todos aquellos numerosos africanos que murieron bajo el estandarte de Alfonso XIII.

117 En el año 1893 el P. Serrallonga destruía por el fuego todas las Comunidades aldeanas de la Isla de Annobón, desplazando poblaciones hacia San Antonio de Palé donde tenían instalada la Misión católica, y organizando milicias armadas para llevar por la fuerza a los indígenas a la iglesia. A principios de 1894 en el internado de Cabo San Juan, el P. Andrés Puiggrós, siguiendo los pasos del ilustre Tomás de Torquemada, ordenó atar y torturar "según las costumbres del país"(sic) a una muchacha libertina, provocando su muerte como consecuencia del trato cruel infligido como punición por el delito de delincuencia de fornicación. A raíz de estos hechos, el informe del P. Josep Mata recoge y justifica varios actos análogos de tortura más severos contra los indígenas, y solicitó el sobreseimiento de la causa [Fernando Ballano Gonzalo, SIAL 2014, PP. 138-139] Si a una libertina le hicieron esto, ¿̇cuánto más a un enemigo de la Corona española y de la Iglesia Católica? 
la declaración prestada por Joaquim Joanola ante Gallo y Martínez (afirmando que los bubis se rindieron nada más ver llegar a los soldados krumanes y el buen trato dado a Ësáasi Eweera), es irrelevante por cuanto que él no es un testigo válido además de haber dicho una mentira religiosa. Los krumanes llegaron de madrugada. Por lo tanto nadie los vio llegar. Por otra parte la supuesta rendición de Ësáasi es un contrasentido por doble partida. Él representaba la última línea de resistencia primaria de los bubis ante la ocupación colonial. El informante Sakká Mueï (Basakato del Oeste, Long Street) señala un rasgo muy importante de esa resistencia al aludir al coraje de aquellos hombres sin miedo a la muerte, fortalecidos mediante la práctica de los torneos y luchas inter-aldeanas: "entre los pueblos bubis se practicaban torneos de enfrentamiento y luchas para aprender el arte de la guerra y fortalecer a los hombres. Se trataba a veces de enfrentamientos a muerte como el último del que me acuerdo, que tuvo lugar a finales del S. XIX entre los pueblos de Rebola y Bakake a causa del 'Sibëtté si abatyapollo'. Esos hombres eran muy valientes e impiadosos" ${ }^{118}$. Obvio es que hombres curtidos en esa clase de peleas no se rendirían ante un escuadrón de fusileros. En el P. Joanola se evidencia de ventaja el deseo de fingimiento; pero a pesar de su lirismo de mal gusto se topa con la máxima según la cual no ha de ser oído el que se contradice a sí mismo ni a aquél que ya mintió sobre un extremo. En su correspondencia de $1^{\circ}$ de julio de 1888 dirigida al P. Manuel Puente, dijo sin ambages disponer del derecho a matar indígenas; y en otra dirigida al P. José (Josep) Mata confesó su participación en el incendio del caserío de Bahú. Abarca anotar en contra del P. Juanola, además, el hecho de que José de la Torre admite haber quemado por lo menos una casa en el valle de Moka. Este dato es importante a la hora de enfrentarnos al criterio del estrago, de la expulsión y del desplazamiento de poblaciones hasta Wâsibè (Bahía de San Carlos) ${ }^{119}$.

En esa dinámica de la disimulación, el 21 de octubre de 1904 se remitió desde Madrid Real orden No 461 exigiendo del Gobernador explicaciones más detalladas sobre la muerte de Ësáasi Eweera. El 6 de febrero de 1905, el Subsecretario

118 En Nations nègres et culture (1979 p. 544) Cheikh Anta Diop señala que la témérité était une des plus hautes valeurs morales, sinon la plus haute, de la société africaine.

119 Reiteramos aquí el nexo de unión entre los acontecimientos del valle de Moka y la insurrección de Balachá, a saber, la mano de obra bubi y las pérdidas de vidas humanas en la construcción de la incipiente ciudad de San Carlos y el dragado manual de la ribera de la bahía para la construcción de la carretera y el puente. "La gente llevaba las piedras a mano", dice Bulebiele Mbatösula. Y confirmaSakká Mueï cuyo padre fue llevado desde Basakato del Este a los trabajos forzosos de dragado y relleno del paso de la carretera de Wâsibè, que según su padre "aquello no fue una broma". 
A. de Castro y Casanis remite al Gobernador, con No 68, un oficio en el que le insta con carácter urgente que despache la otra instrucción que se está llevando a cabo sobre la declaración de "los morenos más prestigiosos de la colonia"; información que el Gobernador se hubo comprometido a materializar, en su informe No 440 con RE en el Ministerio de Estado el 14 de enero de 1905. La disimulación se basa en la figura de "moreno prestigioso"; a saber, aquella persona cuya opinión sería digna de crédito. Los miembros del Consejo de Vecinos de Santa Isabel, agricultores y comerciantes blancos y negros, se incluían en tal categoría, mas por supuesto que no declararían en contra de sus intereses. Los negociantes y agricultores morenos acaudalados (prestigiosos) eran principalmente overseapeoples $^{120}$. Se llamaban William Allen Vivour, Maximiliano Cipriano Jones o Willian Nicol (sierraleoneses), William Napoleón Barleycorn (nigeriano), Antonio Borghes (cubano), Da Cunha (santomense), Toys, Valcárcel, Knox, Kinson, Grange... La presencia de estas personas en la isla de Fernando Poo obedecía a la ocupación de tierras y al enriquecimiento aun a costa de los bubis. No existía razón alguna para que se sintieran indignadas por la muerte de un reyezuelo que lo único que hacía era meterles piedras en los mocasines.

\section{Criptogobierno, secreto e impunidad}

Destaca de la correspondencia entre Madrid y Santa Isabel originada por el caso Eweera el hecho característico de pretender sibilinamente que las autoridades de Santa Isabel hubieron actuado de forma contraria a los principios de la Monarquía española. Esta postura será reiterada por algunos académicos y por el Estado normativo en los sucesos de Balachá seis años después ${ }^{121}$. La pregunta es la de saber si se desprende de los documentos administrativos y religiosos, así como de los hechos futuros y testimonios, que los arcanos de soberanía consumados por el Estado discrecional estaban subrepticiamente compartidos por el

120 En la ciudad de Santa Isabel (actual Malabo) y de San Carlos (actual Luba) la población estaba formada por comerciantes europeos, trabajadores kru y una población criolla resultado de la inmigración producida durante el primer tercio del S. XIX [Alba Valenciano Mañé. "De vestidos y colonización en Guinea Ecuatorial". Debats 123, 2014 p.37] Los fernandinos, que por lo general residen en Santa Isabel y San Carlos, constituyen entre los de la raza negra la aristocracia de la colonia [Temas Españoles No 76, La Guinea Espańola 1954, p. 12]

${ }^{121}$ Lola García Cantús se adscribe a la tesis al concluir acerca de la biografía de Ibarra de Autrán:"tendremos el cuadro de aquello que le determinó a pasar por encima del Ministerio de Estado al ordenar la expedición de castigo contra el poblado de Moka". 
Estado normativo ${ }^{122}$. La Crónica Claretiana del P. Bienvenido Pereda señala que el valle de Moka "fue un gran centro de población. Tuvo la desgracia de que sus reyezuelos y caciques se opusieran radicalmente a la Misión [...] Nada pues ha de extrañar que por fuerza se cumpliera”. Antonio-Manuel Carrasco Gonzáles (2012) hace la constatación de que los territorios guineanos eran territorios extraconstitucionales con un sistema de gobierno indefinido en el aparato estatal; con una legislación especial que reforzaba la omnipotencia de un Gobernador elegido entre personas próximas al Ministro de Estado y a su política. Un poder que constituía una autonomía colonial en una sola persona: el Gobernador, quien concentraba el poder político, militar, administrativo, legislativo y judicial. Cuando Ibarra de Autrán toma la decisión de ir a por Ësáasi Eweera, es hombre de confianza del Ministro de Estado, confía en su misión porque está dotado de poderes omnipotentes que le confiere la especialidad política de Fernando Poo ${ }^{123}$.

En Nations nègres et culture escribe Cheikh Anta Diop: «si l'on veut effacer un peuple pour prendre sa place [...] il faut arriver à désintégrer sa société [...] à la pulvérisation de la partie vivante du passé, à laisser périr les valeurs fondamentales ». He ahí que el Informe No 268 de 26 de julio de 1904 del Gobernador General subraye el "valor inmenso (de la Isla) para "nosotros", y señale "la importancia del servicio prestado por la policía de estos territorios acabando con la 'ridicula leyenda' de los reyes bubis y abriendo paso para el progreso y la civilización [...] Este estado de cosas Seńor [...] hace tiempo debió corregirse [...] si el temor que embargaba a algunas autoridades no se hubiera opuesto a ello". El temor a que se refería el Gobernador es por un lado inexpugnable por cuanto que podría referirse a sentimientos personalísimos; mas por otra parte se trataba del temor a desintegrar la sociedad bubi, a pulverizar la parte viva de su pasado y hacer perecer sus valores fundamentales y sus líderes. Eso explica que en otro oficio del Gobernador, no 273 de 26 de julio de 1904, al Ministro de Estado, diga Ibarra y Autrán lo siguiente: "la importancia del servicio que terminó para

122 El trece de diciembre de 1904 varios autores y cómplices de la destrucción de Maiye, así como del homicidio de Eweera, Passi y Vilobbè, están de fiesta en San Carlos con ocasión de la primera celebración de los festejos dedicados a la Virgen de Montserrat. Asistieron: Ermengol Coll, León García, Antonio Aymemí, Fausto Aliaga, José Sabater. Ibarra y Autrán se encontraba ya enfermo de gravedad y no pudo ser de la fiesta.

${ }^{123}$ Lo mismo que León Rabadán en busca de trabajadores en Balachà. De hecho, el solemne entierro que se le da en San Carlos revela el reconocimiento oficial a un fiel servidor de los arcanos de soberanía. El Diario Claretiano de julio de 1910 relata lo siguiente: "El 26 a las 11 bajaban el cadáver (de León Rabadán y Gómez), estaba bastante acribillado, dos cortes de machete en la cara y cortados los dedos de una mano. Se le enterró con toda solemnidad, habiéndose tributado honores de oficial muerto en campaña”. 
siempre con el poder del Sas [...] recomendar especialmente a V.E. al 1er Teniente de la Guardia Civil señor La Torre por la acertada medida que tomó para la pronta ejecución del servicio". Estamos ante expresiones típicas con las que el Estado discrecional da parte del cumplimiento de los arcanos de soberanía, y a la vez oculta las acciones del criptogobierno. En la misma vertiente, José de la Torre, en su informe a Ibarra y Autrán de 30 de junio de 1904 escribe: "creo, Ilustrísimo Señor, haber interpretado los deseos de su respetable autoridad concluyendo en el Sur de la Isla con el poderío de los bubis”.

Resulta plausible de lo anterior concluir que los secretos del Estado español con respecto de la Isla de Fernando Poo, en concreto contra la jefatura, la forma de gobierno y la autodeterminación bubi, fueron fielmente interpretados y perfeccionados por Ibarra y Autrán, José de la Torre y Silman Sila. Se trataba de esa "barbarie incivilizada de fermentación peligrosa que era necesario atajar a toda costa" (García Cantús. 2009: 21). Arcanos de soberanía que ya fueron acreditados por el P. Juanola al refrendar el derecho a dar la muerte a los hombres superfluos; empoderamiento que se circunscribía, mutatis mutandis, en la Real Orden de 9 de agosto de 1882 por la que el Ministro de Ultramar se obligaba a financiar y apoyar política y militarmente la labor misionera de los hermanos claretianos por la expansión del territorio bajo soberanía española y la "reducción” de los pueblos indígenas (García Cantús 2008: 15). Lola García Cantús encuentra un casus belli en el caso de Balachá, concretamente en las Bases a que deben sujetarse la contratación de bubis (1910), dictadas por Ibarra y Autrán un año antes de la insurrección, a saber, la oposición al trabajo forzoso a través de la servidumbre laboral.

Para mí el pilar de toda esta masacre, los arcanos de soberanía, ha sido siempre la oposición colonialista al derecho a la autodeterminación y a la protección de la tierra de los ancestros bubis; aprovechando la Corona española como casus belli la denegación de la cristianización en las Misiones claretianas y la muerte en esclavitud en la prestación personal obligatoria. Ësáasi Eweera, Bioko y Lubbà lo habían vislumbrado. En nuestro trabajo de campo en Böemëriba, analiza el informante José King lo siguiente: "en el año 1910 el bubi vio que los blancos ya nos querían 'montar', por eso tuvieron el atrevimiento de matar a un blanco; porque lo que es mío es mío". En Ömbôri los informantes señalaron que "si bajaban veinte hombres a trabajar, solamente diez regresaban, los demás habían muerto”. En Ömbôri (Bocoricho Pequeño), hay dos chozas tradicionales de gran valor. Una pertenece al espíritu Lubbà, y la otra es del espíritu Bioko. La elección de si un acto tradicional ha de realizarse en un lugar o en el otro, depende de la 
decisión de los espíritus. El espíritu de Lubbà se revela a través de la sierva Ángela Mòityé, quien cada ańo viaja a Ömbôri a llevar a cabo los ritos memoriales. Por eso es importante analizar estos hechos desde una perspectiva global. Estamos ante la misma resistencia, salvo que una parte se libró contra la ocupación territorial de la zona austral, y la otra contra el dominio y la subyugación de las personas por el Oeste. Por lo tanto, es delicado explicar la muerte de Lubbà sin relacionarla con la de Eweera; ni podemos estudiar los motivos fundamentales de los acontecimientos del valle de Moka si no los correspondemos con la revuelta de Balachá.

\section{Las victimas del valle de Moka}

Todas las resistencias primarias a la ocupación colonial engendran muertes. La Isla de Fernando Poo no debería ser una excepción. ¿Cuántas personas fueron eliminadas antes de la rendición y la captura de los bubis entre el 27 y el 28 de junio de 1904? ¿Cuántos niños maltratados, secuestrados, dejados morir o eliminados?, ¿`cuántos enfermos y ancianos abandonados a su suerte? ¿Cuántos rehenes perecieron de camino a Concepción? Un mes después del fallecimiento de Ësáasi Eweera, el padre Sotero Gómez escribió una correspondencia datada el 25 de julio de 1904, dirigida al padre Juanola. En la misiva, redactada en un castellano caótico, esquiva la pregunta sobre el número de víctimas, y se coligue que el Escuadrón de Silman Sila robó más de noventa cabezas de ganado, o que hubo otro estrago en las mismas fechas en el que también se denuncia una masacre de cabras. En autos bajo intervención de Francisco-Javier Gallo y Martínez se hace mención de cien cabezas de ganado. Si sobre el ganado robado se miente, ¡cuánto más a propósito de las víctimas humanas! Razón por la que el revisionismo histórico quiere imponer el cero, porque la prestidigitación de cadáveres conlleva el desvanecimiento de la imputabilidad del crimen de asesinato u homicidio, permite la confiscación del deber de memoria. Tanto en el valle de Moka como en Balachá, los archivos oficiales son concordantes a la hora de ocultar muertos. A los efectos de lanzar una presunción válida acerca de las bajas humanas y el área de estrago que pudo haberse dado durante los acontecimientos de junio de 1904, importa acercarnos a criterios corroborativos que aumentan seriamente la probabilidad de nuestras conclusiones.

Para ello es significativo puntear que en los tiempos de los acontecimientos, los pueblos de la zona del valle de Moka hasta la comarca de Ureka eran 
Comunidades aldeanas preargelejanas ${ }^{124}$ compuestas de varias poblaciones próximas, en las que se acomodaban pocas o muchas familias ${ }^{125}$. En el Censo de la población bubi de la Isla de Fernando Poo en el año 1901 hecho por el P. Aymemí, publicado en la revista Guinea Española de 25 de abril de 1920 (Año XVII, No VIII) se registran 20 Comunidades aldeanas entre Biapa Alto y Biapa Bajo. Según la descripción dada en el no 19 de la Revista Guinea Española, p. 4, "llegamos a un lugar donde tiene su residencia $S a s[\ldots]$ se compone de varios pueblecitos y cada uno de ellos tiene unas ocho o diez chozas". Algunas Comunidades aldeanas como las ilustradas en el libro de Antonio Aymemí, Los bubis en Fernando Poo, eran más importantes y aglomeraban varias casas. Beltrán Rózpide nos habla de "rancherías y pueblos formados por unas cuantas chozas que no suelen pasar de cien; hay sin embargo alguno que otro poblado mayor, como el de Rebola [...] compuesto de unas 300 chozas". En enero de 1909 en su visita a la Comunidad aldeana de Ureka, el P. Galarza consideró una media de 200 habitantes. El "censo" de Aymemí arriba referido recoge Comunidades aldeanas como Ribiribiri ${ }^{126}$, Maiye ${ }^{127}$, Kutari (Köodáari), Boho (¿Bohé?), con 126, 108, 539, 193 habitantes respectivamente. Estos datos obligan a la reticencia cuando de Maiye solamente quedan poco más de cincuenta personas llevadas como rehenes; de entre ellas sólo 21 adultos y ningún anciano ${ }^{128}$. Empero existe otra inquietud: la población infantil. De los 52 rehenes tomados por Silman Sila, solamente 11 niños llegaron vivos a Santa Isabel. Sencillamente podría tratarse de aquellos niños de pechos cuyas madres protegieron hasta Santa Isabel, habiendo los demás sido matados, huido a otras Comunidades aldeanas y/o entregados de fuerza a la Misión de Concepción para su cristianización. Sobre este último aspecto queda mucho por indagar y desvelar: ¿cuántos niños fueron secuestrados e internados en 1904 ? $^{129}$ ¿Qué castigos se inferían de la prohibición de hablar su idioma y de ejercitar sus ritos?; ¿`cuántos sucumbieron a la práctica rutinaria de

124 Llamadas comúnmente "rancherías"

125 Hemos visionado imágenes del Archivo Claretiano en las que se ven claretianos "visitando un poblado". En varias de dichas fotografías hemos podido apreciar un número de población bastante elevado, y, particularmente muchos niños.

126 Donde residía el bötúuku Malabo

127 Residencia de ËsáasiEweera

128 Esto se deduce del hecho de que los rehenes salieron a pie desde Maiye hasta la bahía de Concepción. Caminata letal para un anciano, aparte de que su lentitud retrasaría la columna.

129 He aquí otro acto con propósito que hace de lazo entre los acontecimientos del valle de Moka y la revuelta de Balachá, y se trata del secuestro de personas para cristianizarlas en un caso, y para esclavizarlas en trabajos forzosos en otro. 
castigos físicos y psicológicos?, ¿a los abusos sexuales?, ¿la mortandad por malnutrición y enfermedades? ${ }^{130}$

De si Sas Ebuera fue objeto de trato cruel e inhumano, y rindió pleitesía a Alfonso XIII.

La cuestión que aquí tratamos de poner en tela de juicio es la afirmación de que Ësáasi Eweera y Passi arribaron a la Misión de Concepción enfermos de gravedad, y de cómo al bötúkkuböóte lo transportaron en una hamaca, falleciendo días después en el Hospital Reina Cristina ${ }^{131}$. Por otra parte, es menester aclarar la cuestión de la pleitesía rendida por el bötúkku-böóte al rey de España; y por último, diagnosticar lo del trato cruel e inhumano que supuestamente no sufrieron los bubis de Maiye entre el 26 de junio y el 5 de julio de 1904.

En la Revista La Guinea Española, no 32, Año II de 12 de julio de 1904, los claretianos publican el artículo "Lo del Rey de Moka": Sas Ebuera falleció "no por castigos ni mal trato, pues se le cuidó muy bien, sino víctima de sus grandes achaques y enfermedades que le hacían digno de compasión y lástima”. A su vez, alega el Gobernador que una vez enterado de la llegada de Sas Ebuera a Santa Isabel y de su estado de salud, lo hizo ingresar en el hospital en una "cama de preferencia". Para quien se haya leído algo sobre la colonización espańola la mentira aquí es nauseabunda y vejatoria. Escribe Plumelle Uribe que "el látigo fue el castigo corporal más frecuente, en los territorios gestionados por los españoles [...] la flagelación era a veces acompañada de otros tormentos" (Plumelle 2001:80). Elikia M’Bokolo nos relata las atrocidades que boers,

130 En el No 20, Año II, de La Guinea Española de 12 de enero de 1904, el artículo "La civilización de la Guinea Española" hace gala en pro de la civilización, de "los castigos que se imponen a los que no hablan nuestro idioma".

131 En la revista La Guinea Española, no 33 de 28 de julio de 1904, en la crónica sobre Estado Sanitario del mes de junio, se señala el ingreso de un moreno "con fractura del húmero izquierdo, magullamiento del brazo derecho, fractura complicada de la articulación tibio peroneatarsiana y extensas encisiones en la espalda. El Director del hospital redujo la fractura del húmero y practicó la cura de primera intención de las demás lesiones, y al día siguiente, éste en unión del médico Sr. Fabre, practicó la amputación de la pierna izquierda”. En el Estado Sanitario del mes de julio, Guinea Espańola no 34, se habla de 21 fallecidos morenos, pero sin referencia alguna a Sas Ebuera, de cuyo cadáver no se supo absolutamente nada. En el caso del bötúkku Luba, de su cadáver tampoco se supo nada una vez confiscado por el criptogobierno, salvo que, cuentan los informantes de Belebú y Böemëriba, fue enterrado en la ciudad de San Carlos, ahí donde se erige la pequeña imitación de un obelisco. 
ingleses, alemanes y portugueses cometieron en África austral ${ }^{132}$. Y no existe razón alguna para que Ësáasi y su gente recibieran un trato de favor diferente al que se dio a los cubanos y haitianos, o al jefe de los Nama, a Hendrik Witbooi, o al soberano Bambata; que es exactamente aquello que primero Rabadán, y luego los blancos de Luba y los trabajadores extranjeros apoyando a los soldados del ejército español, tenían la intención de realizar en Balachá en el año 1910. Toda la historia colonial aboga ruidosamente por el suplicio del bötúkkuböóte. La barbarie inherente a los poderes del Gobernador y a los de Joaquim Juanola claman por la tortura. No se registra absolutamente nada en la historia de la ocupación y la subyugación colonial que defienda una tesis de clemencia hacia el bötúkkuböóte.

La referencia a la hamaca en la que habría sido transportado Eweera es básica en esta reflexión, y conduce a un axioma y a una ironía del destino. El axioma que se infiere del asunto es que si Ësáasi Eweera fue hecho prisionero en Maiye bajo enfermedad en fase terminal, que desde la Misión de Concepción se le tuvo que transportar en hamaca para llevarlo a Santa Isabel; de ello se infiere que tuvo que ir a pie en época lluviosa desde Maiye hasta la Bahía de Concepción. Por lo tanto, queda de manifiesto que Silman Sila y José de La Torre tuvieron la meridiana intención de infligirle un trato tal que de forma razonable y probable le causaría la muerte, lenta, pero segura y a muy corto plazo. Pues confiesan indirectamente haber ańadido aflicción al afligido, lo cual deprava de ventaja su intención criminal. Este razonamiento también es válido para Passi ${ }^{133}$ con respecto del Gobernador. Pues no se explica que en este lapso, salvo para infligirle trato cruel y causarle la muerte, estando Passi también de gravedad, no fuese ingresado en el hospital en la noche del 29 de junio. Passi estuvo encarcelado en la prisión de Santa Isabel hasta fechas próximas al 10 de enero de 1905 en que un informe del Gobernador hace mención de su deceso como consecuencia de unas fiebres $^{134}$ (Luego hablaremos de la ironía del destino. Por ahora interesa el asunto de la pleitesía).

132 L'ère des calamités. ACCT, Paris ABC 1977, PrésenceAfricaine 1988

133 Del relato ofrecido por Mobajale-Dyevola Lele, el hombre de confianza de Eweera llamabo Vilobbè también fue llevado con él a Santa Isabel.

134 Existen datos estadísticos muy interesantes sobre la mortalidad en el hospital Reina Cristina de Santa Isabel. Entre el mes de noviembre de 1903 y enero de 1905, la media de fallecimientos mensuales fue de 8-9-10 negros; salvo en el mes de julio de 1904 donde se arrastraron del mes de junio 31 enfermos, ingresaron 46, y fallecen 21 negros. Un incremento duplicado de la mortandad que no se explica de ninguna manera en la revista La Guinea Española de donde se han extraído las estadísticas hospitalarias; no habiéndose declarado 
Resulta de los registros oficiales que Ësáasi fue capturado y llevado a Santa Isabel para que ante el Gobernador Ibarra rindiese pleitesía y total sumisión del pueblo bubi al Rey Alfonso XIII. Este argumento, teniendo en cuenta los hechos, es traído del absurdo. Primero, desde la Misión de Concepción era evidente, considerando la tesis del estado terminal, que de nada servía arrastrar a un Eweera moribundo ante el Gobernador puesto que era improbable que se expresara en tal estado. Segundo, se sigue del informe de José de La Torre de 30 de junio de 1904 que este individuo amenazó con un daño caracterizado a los bubis en la Misión de Concepción, en el sentido de que "si prometían ser fieles a España y cumplir las órdenes de su gobierno, volverían a sus casas [...] sin sufrir dańo alguno ${ }^{135 "}$. Es válido aquí el argumento que se forma en sentido contrario. No regresaron a Maiye los bubis. De lo que se coligue que el bötúkkuböóte y los suyos sufrieron daño porque Ësáasi Eweera no rindió homenaje ni reconoció la soberanía de Alfonso XIII sobre la tierra ni la vida de los bubis. El hecho de que una vez muerto el bötúkkuböóte los rehenes fueran embarcados (el día 1 de julio si diésemos crédito a las manifestaciones del Gobernador) y trasladados a la ciudad de San Carlos, localidad en construcción que precisaba de habitantes y mano de obra, desmiente abiertamente la afirmación de que se les hubiera traído para rendirle pleitesía al Rey de España, y deja percibir la intención de deskulakizar hacia la incipiente ciudad de San Carlos.

En lo referente al trato cruel e inhumano, todas las declaraciones prestadas ante Francisco-Javier Gallo y Martínez juran y perjuran que Ësáasi Eweera no sufrió maltrato sino murió de vejez extrema. En su correspondencia de 12 de agosto de 1904 el Delegado de Gobierno de San Carlos alegó que [...] durante la singladura hasta Santa Isabel ninguno de los bubis fue maltratado por el ejército. El doctor Arturo Gill Favre insistió a su vez en que Ësáasi Eweera murió de "vejez extrema”. El único disidente es el P. Antonio Aymemí, quien señala la muerte de Sas Ebuera por inanición el 3 de julio ${ }^{136}$. En un caso como en otro sin embargo,

epidemia alguna en Santa Isabel en aquellas fechas. Lo que deja entender que estamos ante "casos excepcionales" de muerte. Pues las estadísticas de octubre, noviembre y diciembre de 1904 decaen de nuevo en 9, 14 y 9 muertos respectivamente. De ello se sigue que probablemente Sas Ebuera y Passi no fuesen los únicos bubis de Maiye que perecieron en el hospital de Santa Isabel entre el 29 de junio y el 30 de julio de 1904.

135 La apuesta entre León Rabadán y Lubbà va en el mismo sentido, en la medida en que Lubbà deja claro que él y su gente no se someterían a los designios de ningún soberano ni a las exigencias de ningún empleador.

136 A. Aymemí (1942: 194). Arturo Gil Fabre declaró que Sas Ebuera fue ingresado en el hospital Reina Cristina el día 2 de julio de 1904, y el P. Aymemí señala que Sas falleció en dicho hospital el día 3 de julio por inanición. Un solo día de ayuno y se muere. Que es la 
estamos ante otro patrón de actos con propósito; porque tanto si Ësáasi Eweera fuera vilmente torturado y matado por manos asesinas, como que fuese dejado morir de hambre o bajo el sufrimiento de la enfermedad y de la inanición y fatiga, se califica con agravantes el asesinato con ensañamiento o el homicidio por abandono de persona y/o denegación de auxilio. Mas en la correspondencia de fecha 26 de julio de 1904 dirigida al Ministerio de Estado, escribe el Gobernador lo siguiente: "al mismo tiempo el espíritu de respeto y disciplina se ha extendido entre estas gentes, convencidas ahora por la realidad de los hechos, de que en la Isla no existe más rey ni más autoridad que la de S.M. el Rey don Alfonso XIII representado por el Gobernador". De lo anterior se infiere el arrodillamiento de los bubis, conmovidos por la crueldad de que es apto el representante del Rey Alfonso XIII. De un revés de la mano esta frase aparta la idea del suicidio, y ratifica la tortura. Para el bötúkkuböóte Ësáasi Eweera fue un acto de tortura doblar la rodilla ante el destino que se reservaba a su gente. Los rehenes adultos y de ventaja los nińos, sufrieron actos de inhumanidad al ser expulsados de su territorio, destruido su entorno, medios y modo de vida tradicional, obligados a ser testigos impotentes de la decadencia y la "ejecución impune" de sus líderes y protectores, de mala muerte y en tierra inhóspita, no pudiendo hacer nada por evitarlo. El trauma y las heridas de los que sobrevivieron al estrago e incendio de Maiye alcanzaron el grado de lesión mental grave y a la integridad física. Desde esta vertiente, todos, absolutamente todos los rehenes, incluido Vilobbè, Passi y Ësáasi Eweera, recibieron un trato inhumano fundamentalmente grave y con imprudente indiferencia por la vida humana. Y esta realidad ha sido silenciada y ocultada por el revisionismo oficial. El otro agravio que se le hizo a la memoria de Eweera viene recogido en la declaración del P. Joaquín Joanola ante el instructor Francisco-Javier Gallo y Martínez, donde manifiesta el religioso que estando ya en coma Ësáasi Eweera se le administró en contra de su voluntad el bautismo católico con el nombre de Pablo; afirmación que con un lenguaje más sardónico recoge la revista La Guinea Española de julio de $1904^{137}$. El robo de

tesis por la que también opta Nuría Fernández Moreno (2013): "He refused to eat for fear of being poisoned and weakened progressively, dying in 1904."

137 Muerto Ësáasi Eweera, la iglesia católica tuvo manos libres para cristianizar en esa región. Resulta de los libros de confirmaciones del Archivo claretiano de la ciudad de Luba, que "en el año del Señor de 1905 y a los trece días de octubre", el P. Armengol Coll procedió a la confirmación, en la Misión de Concepción, de un hijo de Bioko, otro de Möóká y una hija de Sas (Antonio de Köodari, Antonio de Riberi y Luisa de Maiye respectivamente). Del mismo archivo consta que el 16 de febrero de 1908 el RP José Hortiz bautizó a dos hijos de Malabo, y en el año 1909 a primero de noviembre, el Vicario Apostólico Armengol Coll procedió en Concepción a la confirmación de cinco hijos de Sas, con la particularidad de que 
almas in articulo mortis fue una práctica claretiana habitual. El Gobernador José de Barrasa, tuvo en febrero de 1891 un desencuentro con el Rdmo. P. Prefecto Ermengol Coll a propósito del bautizo sub conditione in articulo mortis de la protestante Carlota Vivour ${ }^{138}$.

\section{Ironias del destino}

Volvamos a la cuestión de la hamaca en la que según el Gobernador José de Ibarra y Autrán, fue trasportado el bötúkkuböóte. A finales del año 1904, ya muerto Ësáasi Eweera, la salud de José de Ibarra y Autrán declina, de tal suerte que en diciembre era ya incapaz de levantarse de la cama desde donde rubricaba los documentos oficiales. Yaciente, le informaron de su cesantía "con frases bastante duras" 139 . El 25 de febrero de 1905, a su turno, será transportado en hamaca al buque San Francisco, el cual zarpó hacia España a los cinco días. La historia no dice nada acerca del trato que recibió en dicho barco. Pero el cadáver de José de Ibarra y Autrán no llegó a la tierra natal; fue desembarcado en Monrovia, Liberia, donde recibió sepultura lejos de los suyos. En lo referente a José de la Torre y Rey, dice su legajo personal que murió en el mes de abril de 1907, tres años después de matar al bötúkkuböóte. Seis años después, tras provocar la insurrección que dará lugar a la muerte del bötúkku Lubbà, León Rabadán tampoco regresará a su tierra: lo acribillarán en Balachá, le reventarán la cara con un machete y le amputarán los dedos de una mano.

\section{Deskulakización y rehenes}

Resulta de las fuentes administrativas que "los bubis fueron reembarcados a los dos días de llegar, para San Carlos, desde donde se dirigieron a sus aldeas establecidas en el valle de Moka". Esta declaración es importante por varias razones, pero la que ahora interesa es la manifestación indirecta que se sigue. En ella se reconoce expresamente una consciente deskulakización de ciertas Comunidades aldeanas tendiente a expulsar a los bubis de su hábitat, forzándoles a ir a mendigar espacio y sobrevivir de cualquier manera en tierras lejanas, o rendirse en última instancia a las Misiones católicas o en las incipientes ciudades como San Carlos y Santa Isabel, necesitadas de feligreses, habitantes, mano de obra gratuita o barata.

ya no son naturales de Maiye sino de Riabba. Se trata de: Melchor, Alfonso, Victoria (aparece como oriunda de Balachá), Francisco y Carmelo.

138 Creus, Jacint y Brunat, Antònia. Misión de Santa Isabel. Ceiba ediciones, 1997, p.88

139 Creus, Jacint y Brunat, Antònia. Misión de Santa Isabel, 1997, p.139. 
La expresión "sus aldeas establecidas en el valle de Moka" es una falacia por cuanto que oficialmente la Comunidad aldeana de Eweera (Maiye) ha sido totalmente desalojada; y, de los más de ciento treinta habitantes que entonces tenía, solamente 50 llegaron vivos a Santa Isabel. Empero el informe del Gobernador es incierto sobre otro extremo. Según la crónica sobre "Movimiento de Barcos" de la Revista La Guinea Española en su no 32 Año II de julio de 1904, el Mogador salió del puerto de Santa Isabel para Concepción el día 25 de junio. La misma revista señala que el Mogador salió después, de Santa Isabel con rumbo a San Carlos, el día 3 de julio; y que el día 4 de julio salió el vapor Aro con rumbo a San Carlos ${ }^{140}$. Por lo tanto, los rehenes, si en realidad fueron conducidos a San Carlos por barco, solamente pudieron haber sido embarcados el día 3 o el 4 de julio.

\section{De la Charte du Mandé a los derechos humanos}

De Ësáasi Eweera se ha dicho mucho. Algunos estudios lo han tratado de cabecilla, otros de conjurado que vela por sus propios intereses ${ }^{141}$. Empero, de todo lo que antecede se sigue una conclusión sumamente elemental; cual es que Ësáasi Eweera, como Lubbà ${ }^{142}$ seis años después, fue apresado y matado simplemente por exigir el derecho a la autodeterminación y a la protección y la propiedad inalienable sobre la tierra de sus ancestros; y que la amplitud y gravedad de tales hechos ha sido silenciada y ocultada política y académicamente. La diferencia es que Ësáasi Eweera perdió su batalla y su pueblo fue diezmado, cuando Lubbà la ganó, acabando así con la prestación personal esclavizadora contra los bubis; aunque los dos perdieron la vida. De cómo perdieron la vida es hasta ahora un secreto de Estado. En el caso de Lubbà, la memoria colectiva

${ }^{140}$ Lo que nos llevó a buscar el conocimiento de embarque del Mogador de 3 de julio de 1904; así como el de vapor Aro del día siguiente; al objeto de verificar si en dichos conocimientos constan en uno u otro de los barcos, el embarque y transporte de los bubis rehenes del Gobernador de los TGG traídos de Biapa Alto, y cuántos. Por desgracia no hemos dado con ninguno de los Conocimientos de Embarque.

141 El memorioso Bulebiele Mbatösula señaló que Eweera fue un bötúkku cruel y dictador, que mató a muchos bubis, sobre todo cuando se oponían a él y contestaban sus opiniones o sus actuaciones.

142 Lola García Cantús califica la muerte de León Rabadán a manos de Lubbà de asesinato (in. Estudios africanos, Ceiba 2008, p. 25). No creo que pueda utilizarse con acierto esta calificación, puesto que Lubbà no fue a buscarlo para matarlo a hurtadillas ni en emboscada; sencillamente Rabadán se enfrentó voluntariamente a un hombre que como él, estaba armado, y lo mató en un enfrentamiento provocado por él, en acto de guerra, yendo él en busca de esclavos para su patria. Ni siquiera puede en su caso hacerse alusión a un homicidio. Murió luchando por España, dio su vida por su patria. De hecho lo enterraron con los honores militares de soldado caído en campaña. 
en Ruiché hace mención de un "traidor", cuyo nombre nos revela el memorioso Bulebiele Mbatösula: Tomás Tohobë. Un punto convergente es que el criptogobierno secuestró los cadáveres de los dos hombres y los enterró a su guisa.

Una de tantas definiciones que se dan del crimen de genocidio es la de un "conjunto de actos consistentes en la privación de cualquiera de los derechos elementales de la persona humana, realizados con el propósito de destruir total o parcialmente una población, en razón a sus vínculos raciales, nacionales o religiosos, o bien realizar actos lesivos de los derechos individuales definidores de la existencia de un grupo nacional, étnico, racial o religioso; con el propósito de destruirlo total o parcialmente". Tanto el crimen de genocidio consumado como su tentativa y frustración son constitutivos de ilícito. De los párrafos que anteceden se desprenden sin duda alguna, los actos, la intencionalidad, las víctimas y el grupo al que pertenecen éstas, en el marco de los acontecimientos de junio-julio de 1904 y julio-agosto de 1910. Esos cuatro elementos constituyen los parámetros definitorios del crimen contra la salvaguarda del ser humano "per se"; y si no se consumó el genocidio, su tentativa y frustración se dieron.

La Charte du Mandé es una declaración de derechos que en el año 1222 la Cofradía de Cazadores del Imperio del Malí dictó para "los oídos del mundo entero". Dice a propósito, que "Por patria, país o tierra de nuestros ancestros, también consideramos sobre todo, a los hombres: Pues cualquier país o tierra, que viera desaparecer a sus Hombres de su superficie, conocerá el declive y la desolación". Asimismo, la Charte du Mandé estatuye "Que cada cual vele por la tierra de sus ancestros [...] cualquier daño causado a una vida clama resarcimiento". Empero, de todos los sucesos ocurridos en la Isla de Fernando Poo desde 1892 hasta 1910, ni "mea culpa" ni medidas concretas de reparación, ni la devolución de los símbolos (sombrero, bastón) robados de Maiye. La cuestión de la autodeterminación ha estado siempre vinculada con intereses económicos y religiosos; y se desprende del hecho colonial en sí. Estamos en los orígenes de un concepto que tomará muchas vidas de balde, y generará una letal dicotomía en derecho internacional: el derecho a la autodeterminación vs derecho a la colonización. Conflicto mutado pocas décadas después en el trance entre autodeterminación vs integridad e indivisibilidad territorial de los Estados-naciones.

Si algo limpio puede salir del fango del discurso de Nicolas Sarkozy en la Universidad Cheikh Anta Diop de Dakar el 26 de julio de 2007, es que dijo muy alto algo que muchos llevan calafateado en los pliegues de su negacionismo histórico: "no he venido a hablaros de arrepentimiento". 


\section{BIBLIOGRAFÍA Y FUENTES:}

AGA 81-06273-0001-0017. Información Instruida con carácter reservado, No 1196, Año 1904.

AGA 81-06273-0026-0037-3 Expte. no 59, Caja 4. Detención y fallecimiento del Botuku Sas.

AGA 81-06273-0038-0051. Informe del Gobierno General de los Territorios Españoles del África occidental, No 440,

AGA 81-06273-0052-0061. Información reservada No 300, sobre los conceptos vertidos por el Señor Juez de Primera Instancia e Instrucción de los Territorios Españoles del Golfo de Guinea, de 13 de agosto de 1904, del Gobernador General al Ministro de Estado.

AGA 81-06273-0052-0061. Real Orden del Ministro de Estado de 21 de octubre de 1904.

AGMS/1a/909T/Exp.0. Hoja de Servicio de José de la Torre Rey

AGMS/1a/911/Exp.01. Hoja de Servicio de José Ibarra y Autrán

Anta Diop, Cheikh (1979): Nations nègres et culture. Présence africaine, Paris-Dakar.

Archivos claretianos. Ciudad de Luba, RGE. Cuaderno de confirmaciones, años 19051909

Archivos claretianos. Ciudad de Luba, RGE. Cuaderno de escritos gubernativos (1892)

Archivos claretianos. Malabo, BN, Santuario Claret. Crónica de la Misión de Concepción. RRPP Bienvenido Pereda y Epifanio Doce.

Archivos claretianos. Malabo BN, Santuario Claret. Crónicas del R.P. Pedro A. Díaz de la Misión de Concepción, 1948.

Aymemí, A. (1942): Los Bubis en Fernando Poo, Madrid.

Bobbio, Norberto (2013): Democracia y Secreto. Fondo de Cultura Económica, México DF.

Bolekia Boleká, Justo (2007): Poesía en Lengua bubi, SIAL Ediciones, Madrid.

Bruneteau, Bernard (2009): El siglo de los genocidios. Alianza Editorial, Madrid.

Canals, Eduardo (1993): El Padre grande de Guinea, Editorial Claret, Barcelona.

Carrasco Gonzáles, Antonio-Manuel (2012): La presencia española en África. La Guinea española, ¿un pais sin ley?, Madrid.

Creus, Jacint (2002): Epistolario del P. Juanola (1890-1905). Documentos de la colonización 8. Ceiba ediciones, Vic.

Diarios claretianos (1910). Santuario Claret, Malabo, BN. Preludios y motivos de la fundación de la Casa de San Carlos, julio de 2010. 
Díaz Matarranz, JJ (2005): De la trata de negros al cultivo del cacao. Ceiba Ediciones, Vic.

(2007) La conferencia del Gobernador Puente Basavé en 1895. Doc. de la Colonización 14, Vic, Ceiba.

Fernández Moreno, Nuria (2007): Jefaturas, Reinado y Poder Colonial: Evolución De La Estructura Política De Los Bubis En La Isla De Bioko.- See more at: http://antropologia-online. blogspot.com/2007/10/jefaturas-reinado-y-poder colonial.html\#stash.toxADE8A.dpuf

Fuentes de memoria colectiva: información prestada por: Milagrosa Lubá descendiente de Lubbà (Böemëriba, agosto de 2015); José King (anciano de Böemëriba, agosto de 2013); el memorioso Bulebiele Mbatösula (Rafael) de Belebú de Balachá (nieto de Mbatösula, copartícipe en la revuelta de Balachá), Sakká Mueï (Basakato del Oeste, Long Street, cuyo padre fue llevado al dragado y relleno de la zona de San Carlos), Sora Mössëpà y Biatyó Töttè (Ruiché, 30 de agosto 29015); Ferro Tokotobe Ma-Cristina (Bokoricho, septiembre de 2015).

García Cantús, Lola (2008): El comienzo de la masacre colonial del pueblo bubi. Ceiba Ed., Vic 2008.

(2009): El trabajo forzado bubi en la colonia española de Fernando Poo. 1891-1912. Betwen Three Continents: Rethinking EG on the Fortieth Anniversary of its Independende from Spain. Hofstra University.

Gaceta De Madrid, Año CCXLIII, 14 de febrero de 1904, Tomo I pg. 629. Cese del Gobernador José de Ibarra y Autrán.

Guinea Española, La: Año I, No I, de $1^{\circ}$ de abril de 1903; Año II, No 23, 28 de febrero de 1904; Año II, No 32, de 12 de julio de 1904; Año II, No 33, de 28 de julio de 1904; Año II, No 34 de 12 de agosto de 1904; Año VII, No 15 de 10 de agosto de 1910; Año XVII, No VIII, de 25 de abril de 1920

La Gándara, José de (1871): Crónicas de Fernando Poo. Madrid.

Plumelle Uribe, Rosa-Amelia (2001): La férocité blanche. Des non-Blancs aux nonAryens. Albin Michel.

Robles Mendo, Caridad (1946): Exploradores cientificos de la Guinea, Madrid.

Sundiata, Ibrahim (1996): From Slaving to Neoslavery. The Bight of Biafra and Fernando Po in the Era of Abolition, 1827-1930, The University of Wisconsin Press. 